\title{
A Dual Frequency Compensation Technique to Improve Stability and Transient Response for a Three Stage Low-Drop-Out Linear Regulator
}

\author{
Anass Slamti ${ }^{1 *}$, Youness Mehdaoui $^{1,2}$, Driss Chenouni $^{1}$, Zakia Lakhliai $^{1}$ \\ ${ }^{1}$ Computer and Interdisciplinary Physics Laboratory (L.I.P.I.), Sidi Mohamed Ben Abdellah University (USMBA), Fez, \\ Bensouda-Fez 5206, Morocco \\ ${ }^{2}$ Research Team in Electronics, Instrumentation and Measurements, Sultan Moulay Slimane University (USMS), Beni-Mellal, \\ Beni Mellal 592, Morocco
}

Corresponding Author Email: anass.slamti@gmail.com

https://doi.org/10.18280/mmep.080208

Received: 17 September 2020

Accepted: 22 December 2020

\section{Keywords:}

power management, system on a chip (SoC), Low-Drop-Out regulator (LDO), stability, minimum load current, transient load regulation, CMOS technology

\begin{abstract}
A novel internal compensation technique named dual frequency compensation is proposed to improve the stability and the transient response of the on-chip output capacitor three stage low-drop-out linear voltage regulator (LDO). It exploits a combination of amplification and differentiation to sufficiently separate the dominant pole from the first non-dominant pole so that the latter is located after the unity gain frequency regardless of the load current value. The proposed LDO regulator is analyzed, designed, and simulated in standard $0.18 \mu \mathrm{m}$ low voltage CMOS technology. The presented LDO regulator delivers a stable voltage of $1.2 \mathrm{~V}$ for an input supply voltage range of 1.35-1.85 $\mathrm{V}$ with a maximum line deviation of $4.68 \mathrm{mV} / \mathrm{V}$ and can supply up to $150 \mathrm{~mA}$ of the load current. The maximum transient variation of the output voltage is $54.5 \mathrm{mV}$ when the load current pulses from $150 \mathrm{~mA}$ to $0 \mathrm{~mA}$ during a fall time of $1 \mu \mathrm{s}$. The proposed LDO regulator has a low figure of merit compared with recent LDO regulators
\end{abstract}

\section{INTRODUCTION}

Many system-on-a-chip (SoC) applications integrate circuit blocks, such as digital, analog and radio-frequency blocks [14]. Charge pump regulators are commonly used to generate high voltages for lighting or memory units $[5,6]$; switching converters are employed to regulate digital blocks, due to their high power efficiency [7, 8]; and low-drop-out linear voltage regulators are used to provide low noise supply voltage with very low ripple for noise sensitive blocks, such as analog/RF circuits $[9,10]$. An example that highlights the present-day importance of voltage regulators and power management blocks can be found in ref. [11], where the power supply requirements for a Code-Division Multiple Access (CDMA) modem of a mobile phone are described. As shown in Figure 1 , LDO regulators play a very important role in the integrated power management unit in modern portable electronic devices [11], they scales down the supply voltage to provide for many various other blocks.

An important issue in LDO voltage regulator design is stability, which has a direct impact on the transient response of this system. In addition, the downscaling of the supply voltage and the decrease of the intrinsic gain of the MOS transistor for nanometric CMOS technologies $[12,13]$ requires the use of multiple stages in the implementation of the LDO regulator, this degrades the close-loop response by the presence of multiple poles, hence the need to develop a robust compensation method. Compensation can be external or internal. Generally, external compensation is achieved with a high value capacitor in the order of $\mu \mathrm{F}$ [14]. As for internal compensation, Miller compensation is one of the most widely used techniques [10], but other techniques and approaches can be found in literature [15-28].

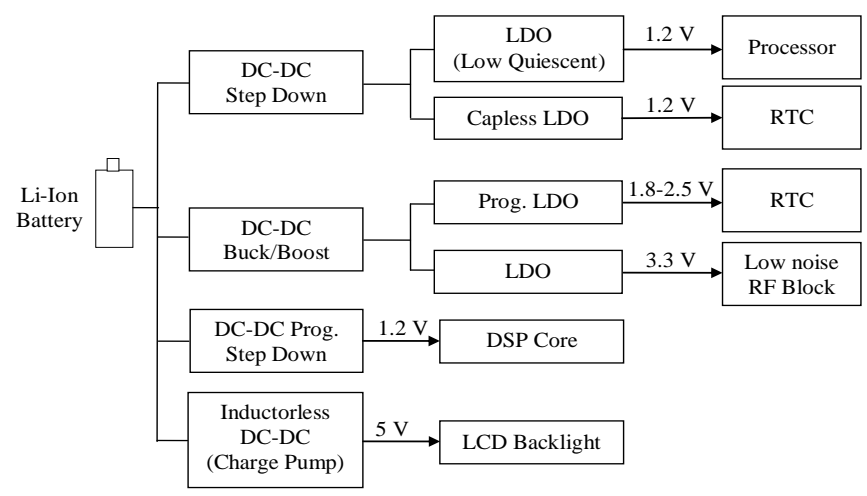

Figure 1. Power management unit in modern portable devices [11]

In this work a novel frequency compensation technique is proposed to achieve the stability for wide range of the load current for the LDO regulator and also enhance his transient response. In section 2, a literature review of stability enhancement is summarized. In section 3, the proposed LDO regulator circuit is given and detailed analysis is performed. In section 4 , the simulation results are given to show the performance of the proposed LDO regulator in terms of stability, transient response and others parameters accompanied by a comparison with previous related works. Finally, in section 5, the simulation results are given to show the performance of the proposed LDO regulator in terms of 
stability, transient response and others parameters accompanied by a comparison with previous related works.

\section{LITERATURE REVIEW OF LDO STABILITY ENHANCEMENT}

Many solutions have been proposed in the literature to improve the stability of LDO regulators with small current load values. One of the earliest proposals [15] uses a compensation block to control the damping factor [16]. This improves the stability of the system and increases the bandwidth. A variant of this work can be found in [17], where a block is introduced to control the quality factor of the pair of non-dominant complex poles. To save power, the active load of the differential pair of the error amplifier is reused as a current buffer. An additional branch is included to introduce a zero in the negative real half-plane with the twofold objective of improving the stability and increasing the maximum current at the gate of pass transistor. Unfortunately, every stage of the control circuit is loaded by compensating capacitors, which causes a decrease in the Slew-Rate (SR) of the LDO regulator. Capacitive multipliers were also used in [18-22]. As an example, in [18], a differentiator, formed by a capacitor and a current buffer, is introduced. This buffer serves a double purpose. First of all, it introduces a fast path between the output of the LDO regulator and the gate of pass transistor. Second, the buffer helps to separate the poles, since the capacitor appears at the gate of pass transistor multiplied by the gain of the current buffer. It is worth noting that the use of a current buffer is compatible with other compensation techniques. As an example, in [22], a current buffer is used as part of a classical Reverse Nested Miller Compensation (RNMC). In [23], adaptive power transistors technique is proposed to allow the LDO regulator to transform itself between two stage and three stage cascaded topologies with respective power transistor, depending on the load current condition. This later technique achieves high stability and good transient response. Most of these techniques and approaches suffer from the instability problem at very low load current, while several applications need the LDO regulator to hold the output and provide good performance under a no-load current condition such as CMOS RAM keep-alive applications.

To overcome the limitations of the classical internal compensation, an alternative topology called Flipped Voltage Follower (FVF) has been proposed [24]. This method has been well analyzed, developed and applied to the LDO regulator [25], it is characterized by a local feedback which makes it possible to achieve a low output impedance, and consequently to improve the SR at the gate of pass transistor, which improves the transient response as well as the stability, but because of the low value of the static gain generated by this method [25], the performance of the line and load regulations remains limited which degrades the transient response. To improve the performance of stability and regulation, several LDO regulators have been proposed, such as the one that uses the Cascode Flipped Voltage Follower [26], the multiple-loop LDO regulator based on the flipped voltage follower [27] and the LDO regulator with mixed internal compensation which marries the Miller compensation and the flipped voltage follower [28].

\section{PROPOSED LDO REGULATOR}

\subsection{Main blocks of proposed LDO regulator}

The diagram block of proposed LDO regulator is shown in Figure 2, while Figure 3 gives transistor implementation of proposed error amplifier (EA). For error amplifier design, a single-ended two-stage error amplifier with fully differential input is chosen [29], it consists of $\mathrm{M}_{1}-\mathrm{M}_{6}$ transistors, bias current $\mathrm{I}_{\mathrm{B}, \mathrm{EA}}$ and common feedback resistor $\mathrm{R}_{\mathrm{CM}}$. A fullydifferential PMOS $M_{1}$ input stage is used to achieve high power supply noise rejection. The third stage is composed by the PMOS pass transistor $M_{P}$ to achieve low dropout voltage [10]. The feedback network is composed by the resistors $R_{\mathrm{FB} 1}$ and $\mathrm{R}_{\mathrm{FB} 2}$. $\mathrm{R}_{\mathrm{L}}$ is the load resistor which models the low voltage system-on-chip powered by the LDO regulator output. The load capacitor $C_{L}$ is integrated on chip, which is essential to improve the transient response. $\mathrm{V}_{\mathrm{I}}$ is the power supply input voltage, $V_{R E F}$ is the reference voltage provided by another subcircuit, $\mathrm{V}_{\mathrm{G}, \mathrm{P}}$ represent the voltage at the gate of pass transistor $M_{P} . V_{O}$ is the output voltage of LDO regulator. The compensation network will be clarified later in this section.

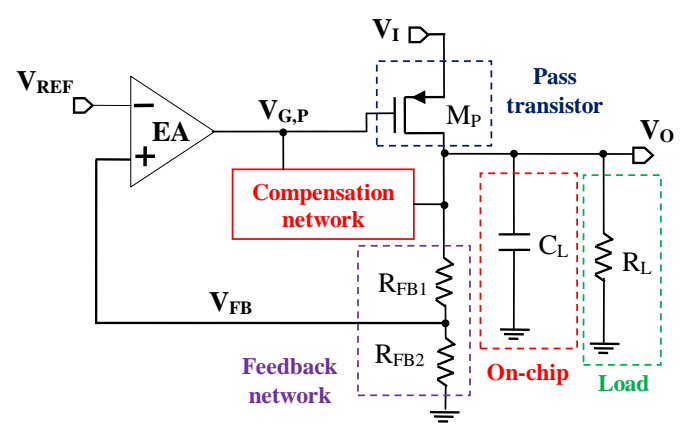

Figure 2. Block diagram of the proposed LDO regulator

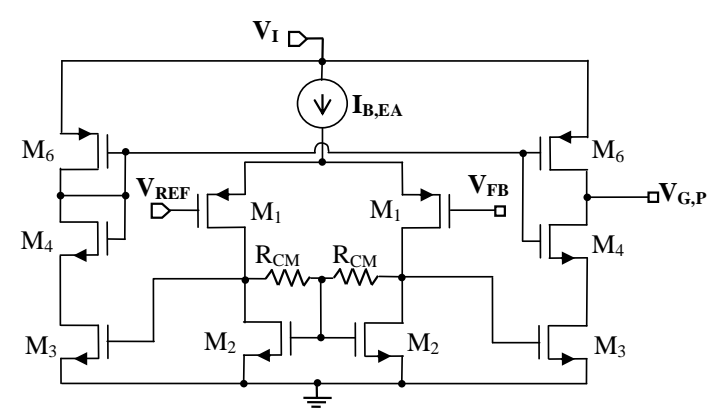

Figure 3. Proposed error amplifier (EA)

\subsection{Stability analysis}

\subsubsection{Uncompensated frequency response}

To determine the uncompensated open-loop transfer function, of the proposed LDO regulator system, defined by Eq. (1), a small signal model is established and it is represented in Figure 4. By applying the Kirchhoff current laws, we obtain the transfer function $\mathrm{H}_{\mathrm{ol}, \mathrm{u}}(\mathrm{s})$ given by Eq. (2). Where, $\mathrm{H}_{0, \mathrm{u}}$ is the DC gain given by Eq. (3), where $\beta$ is the feedback factor expressed by Eq. (4). $g_{m 1}$ is the transconductance of the EA first stage which is equal to that of transistor $\mathrm{M}_{1}$ and $\mathrm{R}_{\mathrm{O} \text {,EA }}$ represents the output resistance of the EA first stage expressed by Eq. (5), where $r_{01}$ and $r_{02}$ represent the small output resistances of transistors $M_{1}$ and $M_{2}$, respectively. $g_{m 3}$ and $g_{m, P}$ 
represent the transconductance of EA second stage, which is equal to that of transistor $\mathrm{M}_{3}$, and the transconductance of pass transistor $M_{P}$, respectively. $r_{06}$ is the small signal output resistance of EA second stage which is equal to small signal output resistance of transistor $\mathrm{M}_{6} . \mathrm{R}_{0}$ is the output resistance of LDO regulator given by Eq. (6), where $r_{o, P}$ is the output resistance of $\mathrm{M}_{\mathrm{P}}$. Note that $\mathrm{s}$ denotes the complex variable of Laplace.
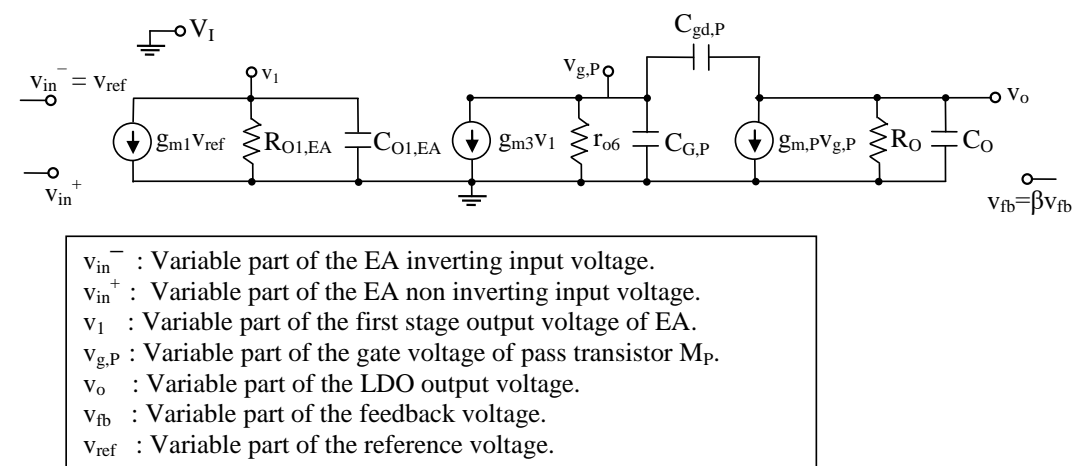

Figure 4. Small signal model of the proposed uncompensated LDO

$$
\begin{gathered}
H_{o l, u}(s)=\frac{v_{f b}}{v_{r e f}} \\
H_{o l, u}(s)=\frac{H_{0, u}\left(1+\frac{s}{z_{R H P}}\right)}{\left(1-\frac{s}{p_{d}}\right)\left(1-\frac{s}{p_{n d}}\right)\left(1-\frac{s}{p_{3}}\right)} \\
H_{0, u}=-\beta g_{m 1} g_{m 3} g_{m, P} R_{O 1, E A} r_{o 6} R_{O} \\
\beta=\frac{R_{F B 2}}{R_{F B 1}+R_{F B 2}} \\
R_{O 1, E A}=r_{o 1} / / r_{o 2} / / R_{C M F B} \\
R_{O}=r_{o, P} / /\left(R_{F B 1}+R_{F B 2}\right) / / R_{L}
\end{gathered}
$$

The transfer function contains a right half-plane (RHP) zero $\mathrm{Z}_{\mathrm{RHP}}$ given by Eq. (7), where $\mathrm{C}_{\mathrm{gd}, \mathrm{P}}$ is the parasitic drain-tosource capacitance. The frequency location of $z_{R H P}$ changes with load current $I_{L}$ (or value of $R_{L}$ ), because $g_{m, P}$ and $C_{g d, P}$ change with $I_{L}$ and this is due to the fact that $M_{p}$ changes the region of operation according to the variation range of $\mathrm{I}_{\mathrm{L}}$ [9].

$$
z_{R H P}=\frac{g_{m, P}}{C_{g d, P}}
$$

According to Eq. (2), the transfer function contains three left half-plane (LHP) poles $\mathrm{p}_{\mathrm{d}}, \mathrm{p}_{\mathrm{nd}}$ and $\mathrm{p}_{3}$, where their locations change relatively with the load current. The dominant pole $p_{d}$ is located at the gate node of $\mathrm{M}_{\mathrm{P}}\left(\mathrm{v}_{\mathrm{g}, \mathrm{P}}\right.$ voltage in Figure 4$)$ due to the large value of $\mathrm{C}_{\mathrm{G}, \mathrm{P}}$ and $\mathrm{r}_{\mathrm{o}}$, where $\mathrm{C}_{\mathrm{G}, \mathrm{P}}$ represents the total capacitance connected between the $\mathrm{M}_{\mathrm{P}}$ gate and the small signal ground. The non-dominant pole $\mathrm{p}_{\mathrm{nd}}$ is located at the output node $\left(\mathrm{v}_{0}\right.$ voltage in Figure 4$)$. The third pole $\mathrm{p}_{3}$ represents the high frequency pole and it's located at the first stage output node of EA ( $\mathrm{v}_{1}$ voltage in Figure 4). This last pole is independent of the load current and therefore does not affect the stability. For the proposed LDO regulator design, $\mathrm{M}_{\mathrm{p}}$ operates in sub-threshold region when the load current is at its minimum value $\mathrm{I}_{\mathrm{L}, \mathrm{min}}$, while it operates in the saturation region at the maximum value $\mathrm{I}_{\mathrm{L}, \max }$ of load current. In this case the approximate expressions of these three poles are given by:

$$
\begin{gathered}
p_{d} \approx-\frac{1}{r_{o 6}\left(g_{m, P} R_{O} C_{g d, P}+C_{G, P}\right)+R_{O} C_{O}} \\
p_{n d} \approx-\frac{r_{o 6}\left(g_{m, P} R_{O} C_{g d, P}+C_{G, P}\right)+R_{O} C_{O}}{R_{o 6} R_{O}\left(C_{g d, P}+C_{G, P}\right) C_{O}} \\
p_{3} \approx-\frac{1}{R_{O 1, E A} C_{O 1, E A}}
\end{gathered}
$$

where, $\mathrm{C}_{\mathrm{G}, \mathrm{P}}=\mathrm{C}_{\mathrm{O} 2, \mathrm{EA}}+\mathrm{C}_{\mathrm{gd}, \mathrm{P}}$ and $\mathrm{C}_{\mathrm{O}}=\mathrm{C}_{\mathrm{L}}+\mathrm{C}_{\mathrm{db}, \mathrm{P} .} \mathrm{C}_{\mathrm{O} 1, \mathrm{EA}}$ and $\mathrm{C}_{\mathrm{O} 2, \mathrm{EA}}$ represent the output capacitances of EA first stage and EA second stage, respectively. $C_{\mathrm{gd}, \mathrm{P}}, \mathrm{C}_{\mathrm{gs}, \mathrm{P}}$ and $\mathrm{C}_{\mathrm{db}, \mathrm{P}}$ represent the parasitic capacitances gate-to-drain, gate-to-source and drainto-bulk of the pass transistor $\mathrm{M}_{\mathrm{P}}$.

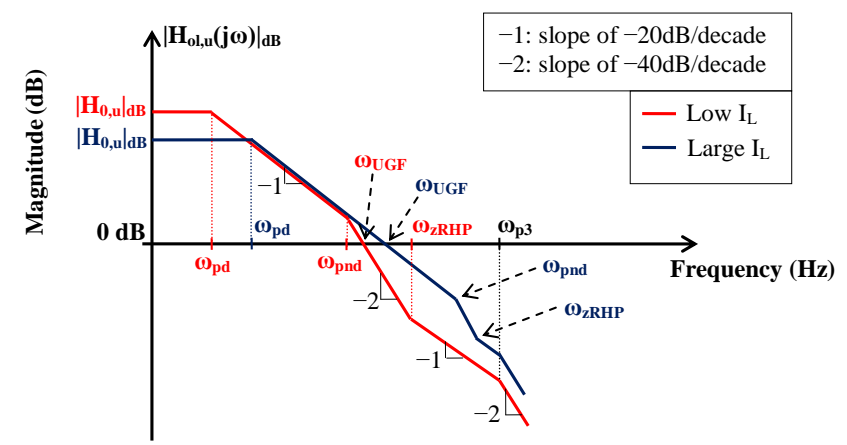

(a) Bode plan location

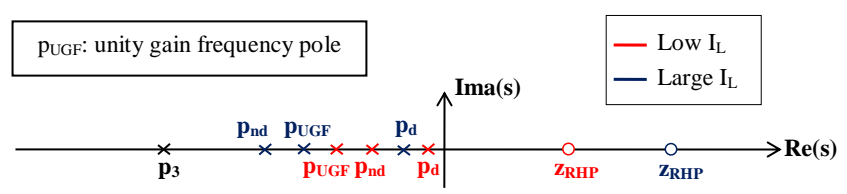

(b) complex s plan location

Figure 5. Pole-zero location with load current variation

Figure 5 shows the dependence of zeros and poles location on the load current $I_{L}$ in the Bode plan and in the complex $s$ 
plane, respectively. The frequency location is presented in term of angular frequency $\omega$, where $\omega_{\mathrm{zRHP}}=\mathrm{Z}_{\mathrm{RHP}}, \omega_{\mathrm{pd}}=-\omega_{\mathrm{pd}}$, $\omega_{\text {pnd }}=-p_{\text {nd }}$ and $\omega_{3}=-p_{3}$. For low $I_{L}$, the RHP zero is located in the middle frequencies, which introduces a phase shift of $-90^{\circ}$, this pushes the non-dominant pole towards the low frequencies, before the unity gain angular frequency $\omega_{\text {UGF. }}$ Therefore the magnitude curve in the Bode diagram intersects the frequency axis by a slope of $-40 \mathrm{~dB} /$ decade and consequently the LDO regulator is unstable. For a case of the large load current, the RHP zero is pushed in the high frequencies, the non-dominant pole is located after the unity gain frequency, so the phase margin is positive but insufficient (less than $45^{\circ}$ ) to stabilize closed loop response of the LDO regulator system.

It is clear that to stabilize the LDO regulator, it is necessary to separate the dominant and non-dominant poles while keeping a phase margin greater than 45 degree for the entire load current range required by the specifications and keeping higher the unity gain frequency to have a fast transient response, this is achieved by adding a LHP zeros well placed with respect to the non-dominant pole and unity gain frequency locations.

\subsubsection{Compensated frequency response}

To stabilize the proposed three stage LDO regulator, a dual compensation circuit has been inserted between the LDO output and the pass transistor gate. The compensation network is given by Figure 6. It is composed of two differentiatorcurrent amplifier blocks, $\left(\mathrm{C}_{\mathrm{C} 1}, \mathrm{R}_{\mathrm{C} 1}, \mathrm{M}_{7}, \mathrm{M}_{8}\right)$ and $\left(\mathrm{C}_{\mathrm{C} 2}, \mathrm{R}_{\mathrm{C} 2}, \mathrm{M}_{9}\right.$, $\mathrm{M}_{10}$ ), whose role is to separate the dominant pole from the first non-dominant pole and to create LHP zeros to increase the phase margin. The proposed compensation block has no effect on the elimination of the RHP zero. The compensation circuit requires a symmetrical bias current $\mathrm{I}_{\mathrm{B}, \mathrm{C}}$. The cascode trasistors $\mathrm{M}_{7 \mathrm{c}}, \mathrm{M}_{8 \mathrm{c}}$ and $\mathrm{M}_{13 \mathrm{c}}$ help to minimize the effect of channel length modulation to improve matching performance.

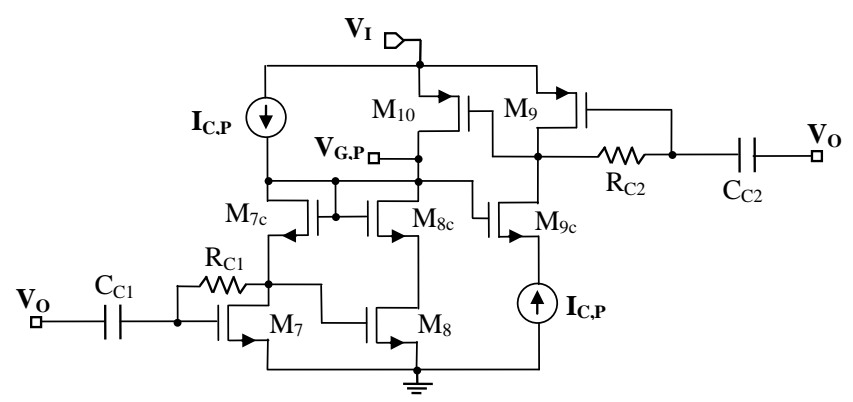

Figure 6. Transistor MOS implementation of proposed frequency compensation circuit

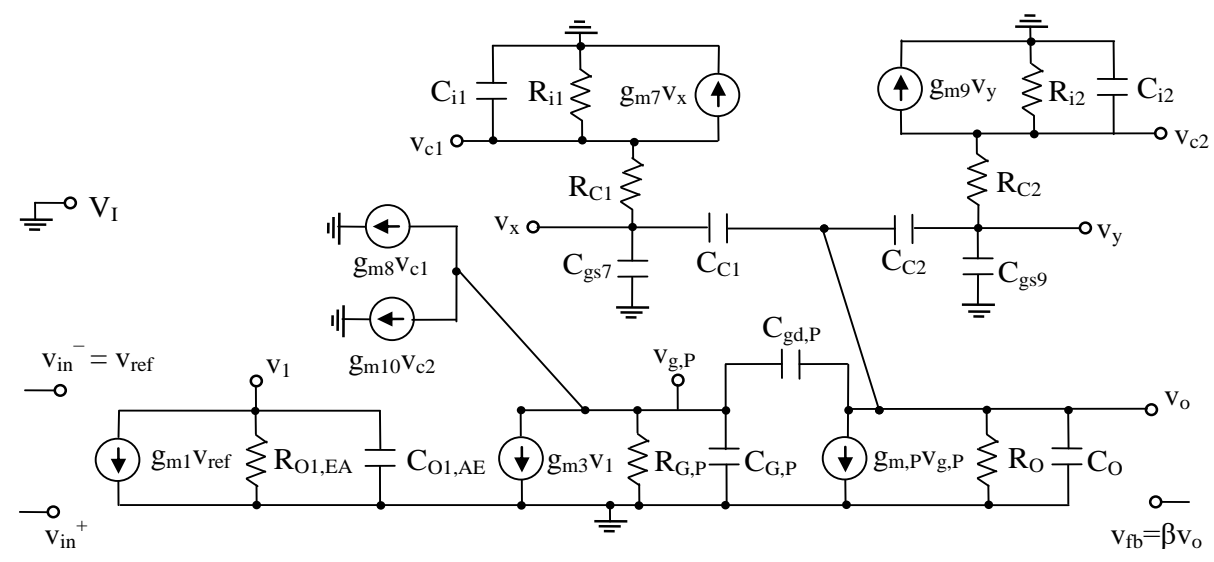

Figure 7. Small signal model of LDO regulator with proposed compensation circuit

To determine the open loop transfer function $\mathrm{H}_{\mathrm{ol}, \mathrm{c}}(\mathrm{s})$ of the compensated system, the small-signal equivalent model was made as shown in Figure 7. By application of Kirchhoff's current law and after some mathematical manipulations and some justified simplifications, we find that $\mathrm{H}_{\mathrm{ol}, \mathrm{c}}(\mathrm{s})$ can be expressed as:

$$
\begin{aligned}
& H_{o l, c}(s) \approx \\
& \frac{H_{0, c} \cdot\left(1+\frac{s}{z_{R H P}}\right)\left(1-\frac{s}{z_{1}}\right)\left(1-\frac{s}{z_{2}}\right)}{\left(1-\frac{s}{p_{d}}\right)\left(1+\frac{a_{2}}{a_{1}} s+\frac{a_{3}}{a_{1}} s^{2}\right)\left(1+\frac{a_{4}}{a_{3}} s\right)\left(1-\frac{s}{p_{5}}\right)}
\end{aligned}
$$

where,

$$
\begin{gathered}
H_{0, c}=-\beta g_{m 1} g_{m 3} g_{m, P} R_{O 1, E A} R_{G, P} R_{O} \\
R_{G, P}=r_{o 6} / / r_{o 10} / /\left(g_{m 8} r_{o 8}^{2}\right)
\end{gathered}
$$

$$
\begin{gathered}
z_{1} \approx-\frac{1}{R_{C} C_{C}} \\
z_{2} \approx-\frac{4}{R_{C} C_{C}}
\end{gathered}
$$

$$
\begin{gathered}
p_{d} \approx-\frac{4}{R_{G, P} g_{m, P} R_{O}\left[\left(g_{m 10}+g_{m 8}\right) R_{C} C_{C}+C_{g d, P}\right]} \\
a_{1} \approx \frac{R_{G, P} g_{m, P} R_{O}\left[\left(g_{m 10}+g_{m 8}\right) R_{C} C_{C}+C_{g d, P}\right]}{4}
\end{gathered}
$$

$$
\begin{aligned}
& a_{2} \approx \\
& \frac{R_{C}^{2} C_{C}^{2}}{4}+R_{G, P} C_{G, P} R_{O}\left(\mathrm{C}_{O}+\mathrm{C}_{\mathrm{C}, t o t}+\mathrm{C}_{\mathrm{g} d, P}\right) \\
& +\frac{R_{\mathrm{C}} \mathrm{C}_{C}}{2}\left[R_{G, P} C_{G, P}+R_{O}\left(\mathrm{C}_{O}+\mathrm{C}_{\mathrm{C}, t o t}+\mathrm{C}_{\mathrm{g} d, P}\right)\right]
\end{aligned}
$$




$$
\begin{aligned}
& a_{3} \approx \frac{R_{C}^{2} C_{C}^{2}}{4}\left[R_{G, P} C_{G, P}+R_{O}\left(\mathrm{C}_{O}+\mathrm{C}_{\mathrm{C}, t o t}+\mathrm{C}_{\mathrm{g} d, P}\right)\right] \\
& +R_{G, P} C_{G, P} R_{O}\left(\mathrm{C}_{O}+\mathrm{C}_{\mathrm{C}, t o t}+\mathrm{C}_{\mathrm{g} d, P}\right) \frac{R_{\mathrm{C}} \mathrm{C}_{C}}{2} \\
& a_{4} \approx \\
& \frac{R_{C}^{2} C_{C}^{2}}{4}\left(\frac{C_{i 1}}{g_{m 7}}+\frac{C_{i 2}}{g_{m 9}}\right) R_{G, P} C_{G, P} \\
& \left.+\frac{R_{C}^{2} C_{C}^{2}}{4}\left(\frac{C_{i 1}}{g_{m 7}}+\frac{C_{i 2}}{g_{m 9}}\right) R_{O}\left(\mathrm{C}_{O}+\mathrm{C}_{\mathrm{C}, t o t}+\mathrm{C}_{\mathrm{g} d, P}\right)\right] \\
& +\frac{R_{C}^{2} C_{C}^{2}}{4} R_{G, P} C_{G, P} R_{O}\left(\mathrm{C}_{O}+\mathrm{C}_{\mathrm{C}, t o t}+\mathrm{C}_{\mathrm{g} d, P}\right) \\
& p_{5} \approx-\frac{1}{R_{O 1, E A} C_{O 1, E A}}
\end{aligned}
$$

$\mathrm{H}_{0, \mathrm{c}}$ represents the DC gain of compensated LDO whose value is very close to the value of $\mathrm{H}_{0, \mathrm{u}}$ previously expressed by Eq. (3). $R_{G, P}$ is the total equivalent resistance connected between the gate node of $\mathrm{M}_{\mathrm{p}}$ and ground. It also includes the output resistances of the two current amplifiers of the compensation circuit as shown by its expression given by Eq. (13). In the term $a_{1}, \mathrm{gm}_{8}$ and $\mathrm{gm}_{10}$ represent the transconductances of the amplifying transistors $\mathrm{M}_{8}$ and $\mathrm{M}_{10}$ of the compensation circuit, respectively. In the term $\mathrm{a}_{4}, \mathrm{~g}_{\mathrm{m} 7}$ and $\mathrm{C}_{\mathrm{i} 1}$ represent the transconductance of $\mathrm{M}_{7}$ and the equivalent input capacitor of differentiator-current amplifier $\left(\mathrm{C}_{\mathrm{C} 1}, \mathrm{R}_{\mathrm{C} 1}\right.$, $\mathrm{M}_{7}, \mathrm{M}_{8}$ ) in compensation circuit. Likewise, $\mathrm{g}_{\mathrm{m} 9}$ and $\mathrm{C}_{\mathrm{i} 2}$ represent the transconductance of $\mathrm{M}_{9}$ and the equivalent input capacitor of differentiator-current amplifier $\left(\mathrm{C}_{\mathrm{C} 2}, \mathrm{R}_{\mathrm{C} 2}, \mathrm{M}_{9}\right.$, $\left.\mathrm{M}_{10}\right)$.

The dominant pole $\mathrm{p}_{\mathrm{d}}$ is located at the gate of $\mathrm{M}_{\mathrm{P}} . \mathrm{z}_{1}$ and $\mathrm{z}_{2}$ are the LHP zeros created by the compensation circuit, where $\mathrm{RC}$ represent the compensation resistance such as $\mathrm{R}_{\mathrm{Cl}}=\mathrm{R}_{\mathrm{C} 2}=\mathrm{RC}$ and $\mathrm{C}_{\mathrm{C}}$ is the compensation capacitance such as $\mathrm{C}_{\mathrm{C} 1}=\mathrm{C}_{\mathrm{C} 2}=\mathrm{C}_{\mathrm{C}}$. The analysis shows that the non-dominant pole corresponds to two complex conjugate poles which are the roots of the polynomial equation presented in the denominator of Eq. (11). The two complex conjugate poles $\mathrm{p}_{2}$ and $\mathrm{p}_{3}$ are given by Eq. (22), where $\omega_{0}$ is the corner angular frequency given by Eq. (23) and $\zeta$ represents the damping factor expressed by Eq. (24). When $\mathrm{I}_{\mathrm{L}}$ continues to increase, the quality factor $\mathrm{Q}=1 /(2 \zeta)$ increases, and the resonance phenomenon appears in the vicinity of the angular frequency $\omega_{0}$, whose resonant angular frequency, noted $\omega_{\mathrm{r}}$, is expressed by Eq. (25). The fourth pole is given by $\mathrm{p}_{4}=-\left(\mathrm{a}_{3} / \mathrm{a}_{4}\right)$, while the fifth pole $\mathrm{p}_{5}$ is located at the output node of the error amplifier first stage. Note that the factorization of the numerator and the denominator of the transfer function was done by the method of time constants described in [30].

$$
\begin{gathered}
p_{2,3}=-\zeta . \omega \pm j \omega_{0} \sqrt{1-\zeta^{2}} \\
\omega_{0}=\sqrt{\frac{a_{1}}{a_{3}}} \\
\zeta=\frac{a_{2} \omega_{0}}{2 a_{1}}
\end{gathered}
$$

$$
\omega_{r}=\omega_{0} \cdot \sqrt{1-2 \zeta^{2}}
$$

As shown in Figure 8, the location of the poles and the RHP zero of the compensated frequency response for proposed LDO changes relatively with load current $\mathrm{I}_{\mathrm{L}}$. Figure 8 shows that the transfer function corresponding to the frequency response of the proposed compensated LDO also contains two other LHP poles $\mathrm{p}_{6}$ and $\mathrm{p}_{7}$ and two other LHP zeros $\mathrm{z}_{3}$ and $\mathrm{z}_{4}$. In the case of the low load current, zero $z_{3}$ cancels pole $p_{6}$ and zero $\mathrm{z}_{4}$ cancels pole $\mathrm{p}_{7}$. Furthermore, the stability analysis shows that for certain low values of $\mathrm{I}_{\mathrm{L}}$, the two complex conjugate poles move towards the right half-plane. Not shown in this paper, Cardan's method [31], allows to solve a cubic equation whose solutions give the poles $\mathrm{p}_{2, \mathrm{i}}$ and $\mathrm{p}_{3, \mathrm{i}}$ represented in Figure 8. To avoid this potential instability, the gate width $\mathrm{Wp}$ of the pass transistor Mp must meet the condition given by constraint (26), where $\mathrm{C}_{\mathrm{O}}=\mathrm{C}_{\mathrm{L}}+\mathrm{C}_{\mathrm{db}, \mathrm{P}}$ and $\mathrm{C}_{\mathrm{C} \text {,tot }}=2 \mathrm{C}_{\mathrm{C}}$. $\mathrm{C}_{\mathrm{gs}, \mathrm{ov}}$ and $\mathrm{C}_{\mathrm{gd}, \mathrm{ov}}$ represent the overloop capacitance gate-to-source and gate-to-drain of $\mathrm{M}_{\mathrm{P}}$, respectively [29].

$$
W_{P} \geq \frac{C_{O}+C_{C, t o t}}{20 C_{g s, o v}-C_{g d, o v}}
$$

For the process used in the proposed design, $\mathrm{C}_{\mathrm{gd}, \mathrm{ov}}=\mathrm{C}_{\mathrm{gs}, \mathrm{ov}}=330 \mathrm{pF} / \mathrm{m}$. Generally $\mathrm{C}_{\mathrm{L}}=100 \mathrm{pF}$ and therefore we can neglect $\mathrm{C}_{\mathrm{db}, \mathrm{P}}$ in front of $\mathrm{C}_{\mathrm{L}}$, hence $\mathrm{C}_{\mathrm{O}} \approx \mathrm{C}_{\mathrm{L}}$. If we choose $\mathrm{C}_{\mathrm{C}}=1 \mathrm{pF}$, we find $\mathrm{W}_{\mathrm{P}} \geq 16586,9 \mu \mathrm{m}$. In conventional LDO design, the minimum value of $W_{P}$ is given by Eq. (27) [10], where $\mathrm{I}_{\mathrm{L}, \max }$ is the maximum output current supplied by an LDO regulator to the load, $\mathrm{V}_{\mathrm{DO}}$ is the maximum dropout voltage and $\mathrm{K}_{\mathrm{p}}$ ' represents a process transconductance parameter of PMOS transistor which is equal in technology used to $96.6 \mu \mathrm{A} / \mathrm{V}^{2}$. For our design specifications, $\mathrm{V}_{\mathrm{DO}, \max }=150 \mathrm{mV}$ and $\mathrm{I}_{\mathrm{L}, \max }=150 \mathrm{~mA}$. If the $\mathrm{M}_{\mathrm{P}}$ gate length $\mathrm{L}_{\mathrm{P}}$ is set to its minimum value of $0.18-\mu \mathrm{m}, \mathrm{W}_{\mathrm{P}, \min }=12422,36 \mu \mathrm{m}$. We observe that the minimum value of $W_{P}$ given by Eq. (26) in proposed design, is greater than that given by Eq. (27) in conventional design. Thus, there is a compromise between the layout area occupied by $\mathrm{M}_{\mathrm{P}}$ and the stability of the proposed LDO regulator system.

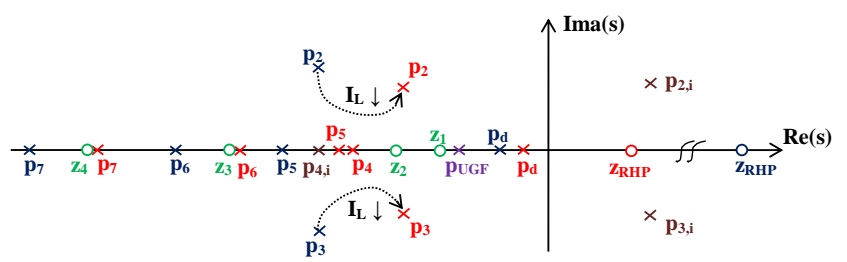

○ Desired positions of LHP

○ RHP zero position for $\mathrm{I}_{\mathrm{L}}=\mathrm{I}_{\mathrm{L}, \text { min }}$

○ RHP zero position for $\mathrm{I}_{\mathrm{L}}=\mathrm{I}_{\mathrm{L}, \max }$

$\times$ LHP poles positions for

$\times$ LHP poles positions for high $\mathrm{I}_{L}$

$\times$ Desired position of unity gain frequency pole regardless of $\mathrm{I}_{\mathrm{L}}$ value

$\times$ Probable instability (complex poles with positive real part) for certain low $I_{L}$ values

Figure 8. Pole-zero location in complex s plane for the proposed compensated LDO regulator

$$
\left(\frac{W_{P}}{L_{P}}\right)_{\min }=\frac{I_{L, \max }}{K_{p}^{\prime} V_{D O}^{2}}
$$


To show the robustness of the proposed compensation circuit, we evaluated the phase margin PM for all required values of the load current. The phase margin of the proposed LDO system is given by:

$$
\begin{aligned}
P M \approx 90^{\circ} & -\tan ^{-1}\left(\frac{\omega_{U G F}}{\omega_{z_{R H P}}}\right)+\tan ^{-1}\left(\frac{\omega_{U G F}}{\omega_{z_{1}}}\right)+\tan ^{-1}\left(\frac{\omega_{U G F}}{\omega_{z_{2}}}\right) \\
& -\tan ^{-1}\left(\frac{\omega_{U G F}}{\omega_{p d}}\right)-\tan ^{-1} Q\left(\frac{\omega_{U G F}}{\omega_{0}}-\frac{\omega_{0}}{\omega_{U G F}}\right) \\
& -\tan ^{-1}\left(\frac{\omega_{U G F}}{\omega_{p 4}}\right)-\tan ^{-1}\left(\frac{\omega_{U G F}}{\omega_{p 5}}\right)
\end{aligned}
$$

To have a sufficient phase margin, it is necessary to place the zero $z_{1}$ in the vicinity of the unity gain angular frequency $\omega_{\text {UGF }}$ and before the resonance angular frequency $\omega_{0}$ of the two conjugate complex poles, the second zero $\mathrm{z}_{2}$ is placed in the vicinity of $\omega_{0}$. If, for example, we choose $\mathrm{f}_{\mathrm{UGF}}=1 \mathrm{MHz}$ and $\mathrm{f}_{\mathrm{z} 1}=$ $1.5 \mathrm{f}_{\mathrm{UGF}}$, from Eq. (15), we will have $\mathrm{f}_{\mathrm{z} 2}=6 . \mathrm{f}_{\mathrm{UGF}}$ and therefore $\mathrm{f}_{0} \approx \mathrm{f}_{\mathrm{z} 2} \approx 6 \mathrm{MHz}$. In this case, and according to Eq. (28), in the worst case where the positive real zero is displaced in the vicinity of the unity gain frequency, the phase margin obtained is equal to $80^{\circ}$. Therefore, the proposed compensation circuit ensures the stability of the LDO regulator for all required values of the load current which represents the desired result.

Finally, the stability condition on the phase margin PM for the proposed LDO regulator system, given by Eq. (29), allows determining the values of $R_{C}$ and $C_{C}$ for the desired value of unity gain frequency $f_{U G F}$.

$$
\begin{gathered}
P M \approx 90^{\circ}+\tan ^{-1}\left(2 \pi f_{U G F} R_{C} C_{C}\right) \\
+\tan ^{-1}\left(\frac{\pi f_{U G F} R_{C} C_{C}}{2}\right)
\end{gathered}
$$

\subsection{Transient response analysis}

Transient response is the dynamic performance of linear regulator [10]. It can be separated into two parts, one is form load variation, named as load transient response, and the other is from line variation, named as line transient response. A typical LDO regulator transient response to load changes is shown in Figure 9.

For an increase of load current by $\Delta \mathrm{I}_{\mathrm{L}}$, the LDO output observes an undershoot $\Delta \mathrm{V}_{\mathrm{O}}$, for a response time duration of $\Delta \mathrm{t}_{1}$. The loop reacts to this load change and the output voltage settles in a time duration defined by reaction time also known settling time $\Delta \mathrm{t}_{2}$. Minimizing $\Delta \mathrm{t}_{1}+\Delta \mathrm{t}_{2}$ is a critical need for digital load applications. The LDO response time $\Delta \mathrm{t}_{1}$ depends on undershoot $\Delta \mathrm{V}_{\mathrm{O}}$, output capacitance $\mathrm{C}_{\mathrm{O}}$ and load current change $\Delta \mathrm{I}_{\mathrm{L}}$, and can be expressed as:

$$
\Delta t_{1}=C_{O} \cdot \frac{\Delta V_{O}}{\Delta I_{L}}
$$

The settling time, $\Delta \mathrm{t}_{2}$ is determined by the open-loop bandwidth $\omega_{\text {pd }}$ of the regulation loop and the slew-rate (SR) at the gate of pass transistor MP and can be written as:

$$
\Delta t_{2}=\frac{2 \pi}{\omega_{p d}}+S R
$$

with,

$$
S R=C_{G, P} \cdot \frac{\Delta V_{G, P}}{I_{S R}}
$$

where, $\Delta \mathrm{V}_{\mathrm{G}, \mathrm{P}}$ and $\mathrm{I}_{\mathrm{SR}}$ represent the voltage change and slewing current at the gate of $\mathrm{M}_{\mathrm{P}}$, and we have $\Delta \mathrm{V}_{\mathrm{G}, \mathrm{P}}$ is proportional to $\Delta \mathrm{V}_{\mathrm{O}}$.

The proposed compensation circuit also improves the transient response by increasing the bias current at the gate of the pass transistor $M_{P}$ via the current amplifier block which amplifies this bias current $\mathrm{I}_{\mathrm{B}, \mathrm{C}}$ during the transient times of the load current, which allows to minimize the slew-rate and consequently to reduce overshoots and undershoots and also to reduce the settling time.

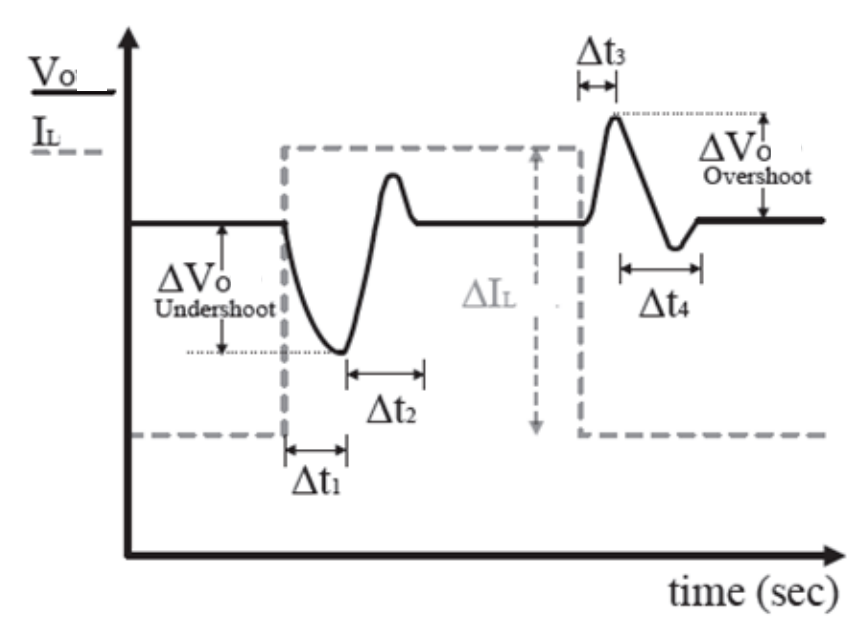

Figure 9. Typical LDO Regulator Load Transient Response

\subsection{Voltage reference}

The LDO regulator proposed in this work also includes the voltage reference, which plays an important role in the accuracy of the feedback voltage $\mathrm{V}_{\mathrm{FB}}$, which is why this voltage reference $V_{\text {REF }}$ must have a precise value and independent of the temperature, the supply voltage and the process of the technology used. The voltage reference designed for the LDO regulator was previously realized and published by the same authors [32]. The value of $V_{\text {REF }}$ is equal to $0.635 \mathrm{~V}$.

\section{SIMULATION RESULTS AND DISCUSSION}

The proposed three stage LDO regulator with dual frequency compensation scheme was simulated in standard $0.18 \mu \mathrm{m}$ CMOS process using Cadence Virtuoso Spectre Simulator.

As shown in Figure 10 in the DC line simulation at maximum load current of $150 \mathrm{~mA}$, the proposed LDO provides a $\mathrm{DC}$ output voltage $\mathrm{V}_{\mathrm{O}}$ of $1.2 \mathrm{~V}$ from a minimum input supply voltage $\mathrm{V}_{\mathrm{I}}$ of $1.35 \mathrm{~V}$. The $\mathrm{DC}$ line regulation is $4.68 \mathrm{mV} / \mathrm{V}$ for input supply voltage variation $\Delta \mathrm{V}_{\mathrm{I}}$ of $0.5 \mathrm{~V}$ from $1.35 \mathrm{~V}$ to $1.85 \mathrm{~V}$, this operating voltage range is limited by the line regulation of the designed voltage reference [32] as shown in Figure 10 (b) 


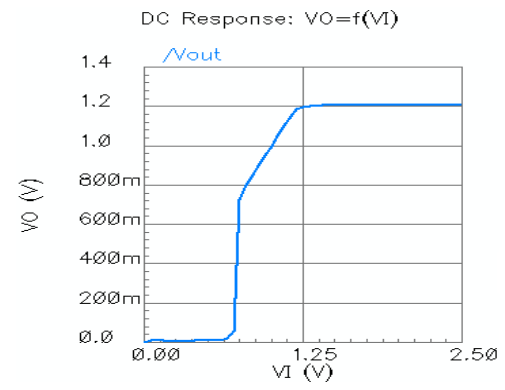

(a) With ideal voltage reference $D C$ Respanse: $V O=f(M)$

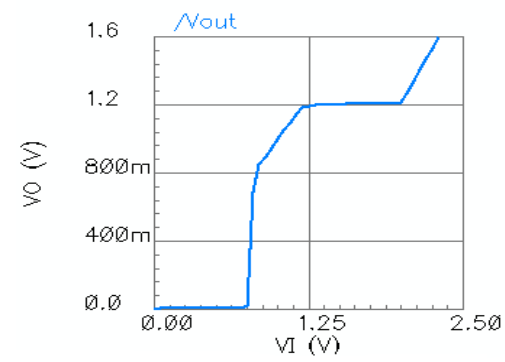

(b) With internal voltage reference

Figure 10. Simulation result of the DC line regulation at maximum load current

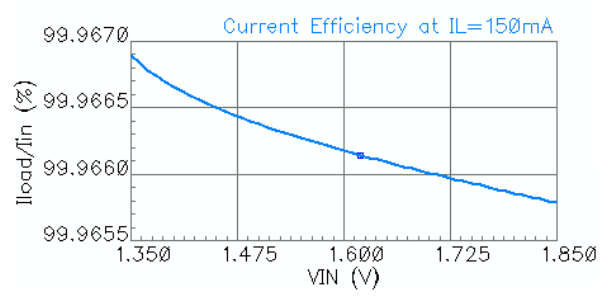

(a) Current efficiency

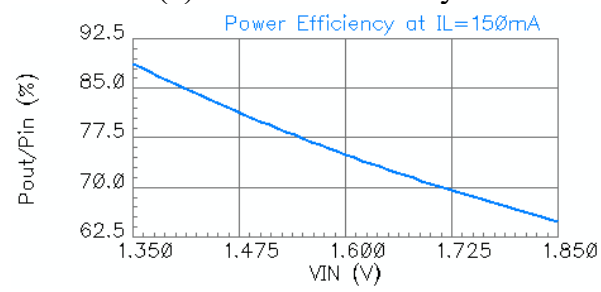

(b) Power efficiency

Figure 11. Simulation result of efficiency at maximum load current

As shown in Figure 11 in the DC efficiency simulation, for $\mathrm{V}_{\mathrm{I}}=1.6$, the current efficiency is equal to $99.9662 \%$ while the power efficiency is $75 \%$ at maximum load current of $150 \mathrm{~mA}$, respectively.

Figure 12 gives the simulation result of the quiescent current. The quiescent current consumed by the proposed LDO regulator in full load condition and under the supply input voltage of $1.6 \mathrm{~V}$ is $10.75 \mu \mathrm{A}$ without voltage reference, while this current is $50.75 \mu \mathrm{A}$ with the internal voltage reference.

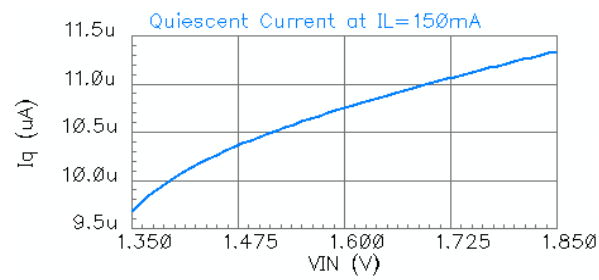

(a) With ideal voltage reference

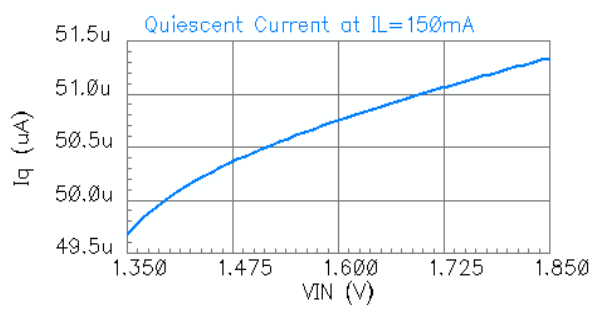

(b) With Internal voltage reference

Figure 12. Simulation result of quiescent current

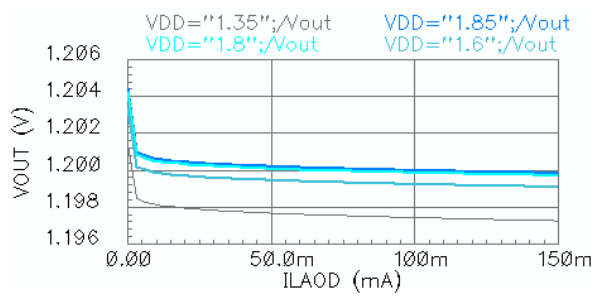

(a) DC load regulation

DC Respanse: Drop-out voltage Versus Laad current

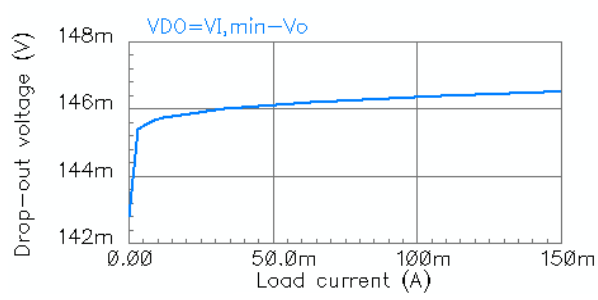

(b) Drop-out voltage

Figure 13. DC load simulation result

As shown in Figure 13 in the DC load simulation, the DC load regulation is equal to $24.2 \mu \mathrm{V} / \mathrm{mA}$ at $\mathrm{V}_{\mathrm{I}}=1.6 \mathrm{~V}$ measured from Figure 13 (a). The proposed LDO regulator has a low value of the drop-out voltage less than $150 \mathrm{mV}$ for all required load current range as shown in Figure 13 (b).

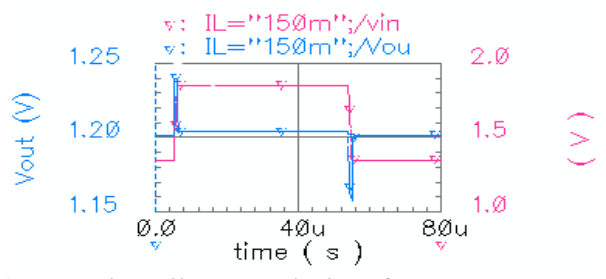

(a) Transient line regulation for $\mathrm{I}_{\mathrm{L}, \max }=150 \mathrm{~mA}$

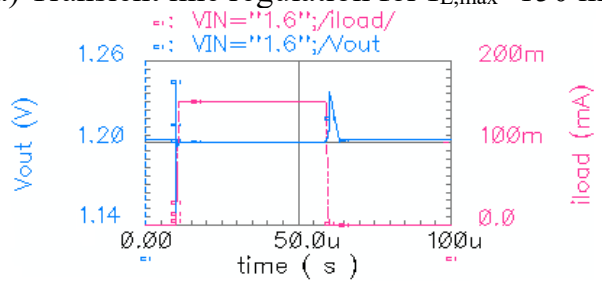

(b) Transient load regulation for $\mathrm{V}_{\mathrm{I}}=1.6 \mathrm{~V}$

Figure 14. Transient simulation

Figure 14 presents the transient simulation of the proposed compensated LDO regulator. As shown in Figure 14 (a), for transient line regulation performed at maximum load current $\mathrm{I}_{\mathrm{L}, \max }$ of $150 \mathrm{~mA}$, the output voltage $\mathrm{V}_{\mathrm{O}}$ presents an overshoot of $19.77 \mathrm{mV}$ when the input supply voltage $V_{\text {I }}$ pulse up from $1.35 \mathrm{~V}$ to $1.85 \mathrm{~V}$ during $1 \mu \mathrm{s}$ of rise time, while $\mathrm{V}_{\mathrm{O}}$ presents an undershoot of $-17.15 \mathrm{mV}$ when $\mathrm{V}_{\text {I }}$ pulse down from 1.85 $\mathrm{V}$ to $1.35 \mathrm{~V}$ during $1 \mu$ s of fall time. As shown in Figure 14 
(b), for transient load regulation performed at input supply voltage $\mathrm{V}_{\text {I }}$ of $1.6 \mathrm{~V}, \mathrm{~V}_{\mathrm{O}}$ presents an overshoot of $44.9 \mathrm{mV}$ and an undershoot of $-50.8 \mathrm{mV}$ when load current pulse up from $0 \mathrm{~mA}$ up to $150 \mathrm{~mA}$ during $1 \mu$ s of rise time, while $V_{O}$ presents an overshoot of $34.1 \mathrm{mV}$ when load current pulse down from $150 \mathrm{~mA}$ down to $0 \mathrm{~mA}$ during $1 \mu$ s of fall time.

Figure 15 shows the open loop AC simulation for all required load current range at input supply voltage of $1.6 \mathrm{~V}$ under $\mathrm{C}_{\mathrm{L}}=100 \mathrm{pF}, \mathrm{R}_{\mathrm{C}}=100 \mathrm{k} \Omega$ and $\mathrm{C}_{\mathrm{C}}=1 \mathrm{pF}$. The proposed LDO is stable for all required current load range. The minimum value of load current $I_{L}$ for normal operation is $50 \mu \mathrm{A}$. The unity gain frequency is practically constant for any value of $I_{L}$ in the required range and it is close to $1 \mathrm{MHz}$, which presents a good performance of the proposed compensation circuit. The AC magnitude exhibits a high frequency peak, its location depends on the value of the load current and this due to the presence of two complex conjugate poles as it has been proved in section 3. Table 1 summarizes the AC simulation performance for the proposed LDO regulator at input supply voltage $\mathrm{V}_{\mathrm{I}}$ of $1.6 \mathrm{~V}$.

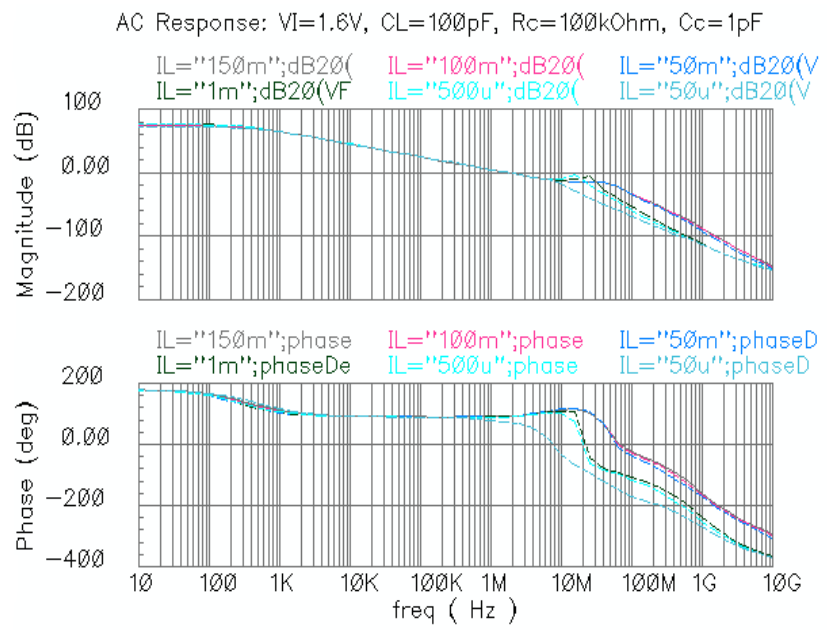

Figure 15. AC open loop simulation for all required load current range

To show the robustness of the proposed dual compensation technique in term of stability with respect to the load current, a comparison with classical compensation methods and others compensation methods cited in this work such as [18] and [21] is performed as shown in Figure 16. The proposed compensation technique ensures stability not only for low values of the load current but also for very low values of the load current, in particular for a zero load current where the phase margin is equal to $45.1^{\circ}$ as it is shown in Figure 16 (b). This result is not achieved by the compensation methods proposed in $[18,21]$. In addition, the proposed compensation circuit uses a total compensation capacitance $\mathrm{C}_{\mathrm{C} \text {,tot }}$ of $2 \mathrm{pF}$, while the authors of $[18,21]$ have used $23 \mathrm{pF}$ and $41 \mathrm{pF}$ respectively to guarantee good stability. The smaller the capacitor to integrate on the chip, the more the layout area is saved.

Table 1. AC simulation performance of the proposed LDO regulator at $\mathrm{V}_{\mathrm{I}}=1.6 \mathrm{~V}$

\begin{tabular}{ccc}
\hline Performance & Mimum load & Full load \\
\hline DC gain $\left|\mathrm{H}_{0, \mathrm{c}}\right|$ & $72.53 \mathrm{~dB}$ & $74.05 \mathrm{~dB}$ \\
Bandwidth $\mathrm{f}_{\mathrm{pd}}{ }^{1}$ & $268.3 \mathrm{~Hz}$ & $220.3 \mathrm{~Hz}$ \\
Gain-bandwidth product & $1.135 \mathrm{MHz}$ & $1.110 \mathrm{MHz}$ \\
$\left|\mathrm{H}_{0, \mathrm{c}}\right| . \mathrm{f}_{\mathrm{pd}}$ & & \\
Unity gain frequency fuGF & $1.139 \mathrm{MHz}$ & $1.113 \mathrm{MHz}$ \\
Phase margin PM ${ }^{2}$ & $84.06^{\circ}$ & $92.08^{\circ}$ \\
Resonant frequency $\mathrm{f}_{\mathrm{r}}{ }^{3}$ & $6.309 \mathrm{MHz}$ & $39.81 \mathrm{MHz}$ \\
${ }^{1} \mathrm{f}_{\mathrm{pd}}=2 \pi \omega_{\text {pd. }}{ }^{2} \mathrm{PM}=180^{\circ}+\operatorname{Arg}\left[\mathrm{H}_{\mathrm{ol}, \mathrm{c}}\left(\mathrm{j} 2 \pi \mathrm{f}_{\mathrm{UGF}}\right)\right] \cdot{ }^{3} \mathrm{f}_{\mathrm{r}}=\mathrm{f}_{\mathrm{pd}}=2 \pi \omega_{\mathrm{r}}$
\end{tabular}

Table 2 summarizes performance characteristics of the proposed LDO regulator and comparison with others LDO regulators cited in this work is given. For comparison of the State of the Art, some Figures of Merit (FOMs) is proposed [33]. Note that the smaller the FOM chosen for this work, the better the regulator. The FOM chosen for the comparison is given by Eq. (33), where $\left|\Delta \mathrm{V}_{\mathrm{O} \text {,max }}\right|$ is the maximum variation of the output voltage $\mathrm{V}_{O}$ in the line voltage or the load current (maximum overshoot or absolute value of minimum undershoot), $\mathrm{I}_{\mathrm{Q}}$ is the quiescent current, $\mathrm{C}_{\mathrm{L}}$ is the load capacitance and $\mathrm{I}_{\mathrm{L}, \max }$ is the maximum load current.

$$
F O M=\left|\Delta V_{O, \max }\right| \cdot \frac{C_{L} \cdot I_{Q}}{I_{L, \max }^{2}}
$$

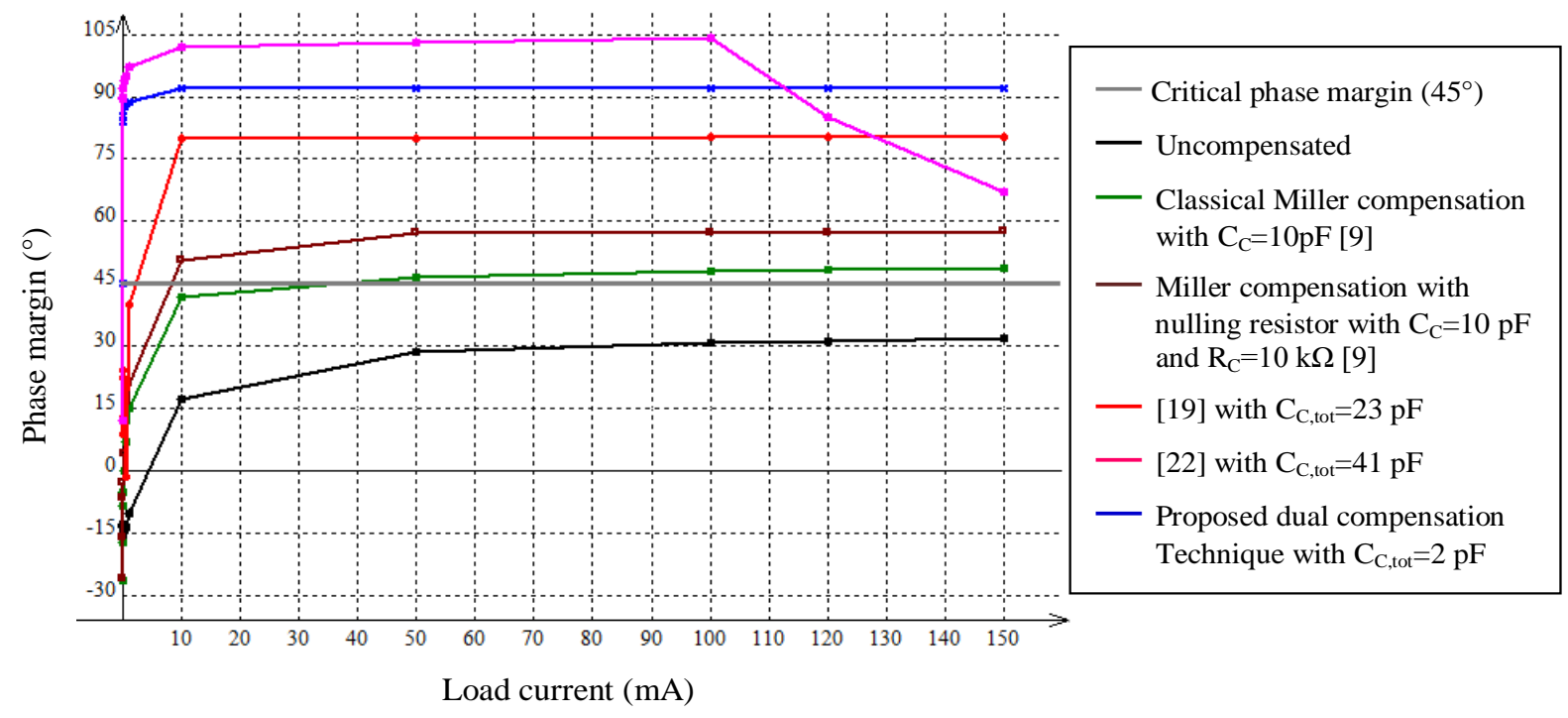

(a) all load current range 


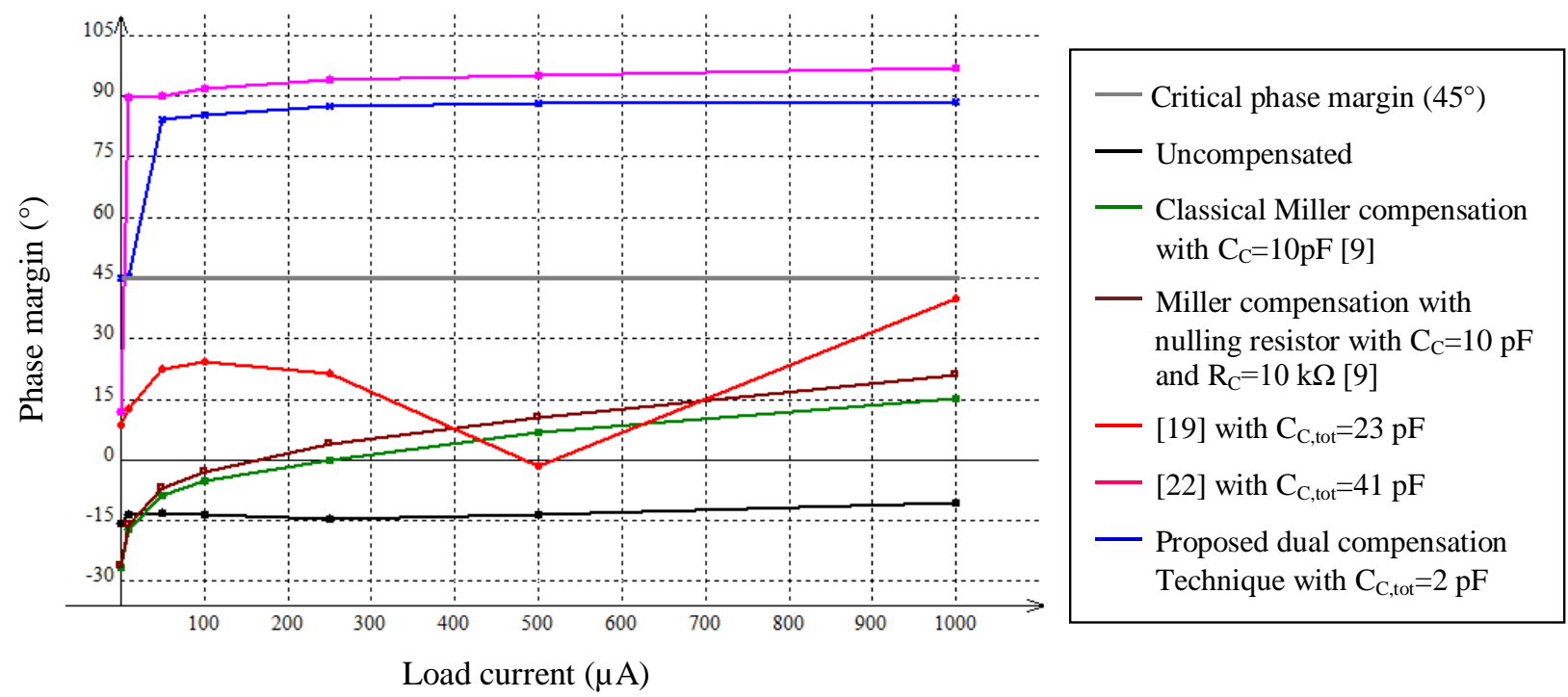

(b) low load current range

Figure 16. Phase margin versus load current for LDO regulator system

Table 2. Performance of proposed LDO regulator and comparison with other LDO regulators cited in this work

\begin{tabular}{|c|c|c|c|c|c|c|c|}
\hline Performance & [17] & [25] & [26] & [27] & [18] & [22] & This work \\
\hline Process $(\mu \mathrm{m})$ & 0.35 & 0.18 & 0.35 & 0.5 & 0.065 & 0.18 & 0.18 \\
\hline Input supply voltage $\mathrm{V}_{\mathrm{I}}(\mathrm{V})$ & $3.0-4.0$ & $1.1-1.5$ & $1.2-1.5$ & $1.4-4.2$ & 1.2 & $1.1-1.5$ & $1.35-1.85$ \\
\hline Output voltage $V_{O}(\mathrm{~V})$ & 2.8 & 1.0 & 1.0 & 1.21 & 1.0 & 1.0 & 1.2 \\
\hline Drop-Out voltage V & 200 & 100 & 200 & 200 & 200 & 114 & 146.6 \\
\hline Maximum load current $\mathrm{I}_{\mathrm{L}, \max }(\mathrm{mA})$ & 50 & 50 & 50 & 100 & 100 & 100 & 150 \\
\hline Quiescent current $I_{Q} @ I_{L, \max }(\mu \mathrm{A})$ & 65 & 54 & 45 & 45 & 82.4 & 20 & $\begin{array}{l}59.68-11.3 \\
649.68-51.3\end{array}$ \\
\hline Current efficiency $\eta_{I} @ \mathrm{I}_{L, \max }(\%)$ & 99.935 & 99.946 & 99.955 & 99.955 & 99.917 & ${ }^{1} \mathrm{~N} . \mathrm{A}$. & $99.968-99.967$ \\
\hline Power efficiency $\eta @ \mathrm{IL}$,max $(\%)$ & ${ }^{1}$ N. A. & ${ }^{1}$ N. A. & ${ }^{1}$ N. A. & ${ }^{1}$ N. A. & ${ }^{1}$ N. A. & ${ }^{1}$ N. A. & $88.8-65.5$ \\
\hline $\begin{array}{l}\text { Minimum on-chip output capacitance } \\
\qquad \mathrm{C}_{\mathrm{L}}(\mathrm{pF})\end{array}$ & $10^{2}$ & $10^{2}$ & $\begin{array}{c}10^{3} \\
\text { (Off-chip) }\end{array}$ & $\begin{array}{c}10^{5} \\
\text { (Off-chip) }\end{array}$ & $10^{2}$ & $10^{2}$ & $10^{2}$ \\
\hline Total compensation capacitance $\mathrm{C}_{\mathrm{C}, \text { tot }}(\mathrm{pF})$ & 23 & 5 & 41 & & & 12 & 2 \\
\hline Transient Line Regulation $\left(\Delta V_{O}\right.$ varying $\left.V_{I}\right)$ & & & & & & & \\
\hline Maximum overshoot (mV) & 90 & ${ }^{1}$ N. A. & ${ }^{1}$ N. A. & 23 & 8.91 & 55.66 & 23.05 \\
\hline Minimum undershoot $(\mathrm{mV})$ & -10 & ${ }^{1}$ N. A. & ${ }^{1}$ N. A. & -12 & -10.63 & -55.34 & -22.49 \\
\hline Transient Load Regulation ( $\Delta \mathrm{V}_{\mathrm{O}}$ varying $\left.\mathrm{I}_{\mathrm{L}}\right)$ & & & & & & & \\
\hline Maximum overshoot (mV) & 80 & 100 & 70 & 47 & 0 & 99.52 & 31.1 \\
\hline Minimum undershoot (mV) & -80 & -80 & -70 & -48 & -68.8 & -591.1 & -54.5 \\
\hline${ }^{2}$ Response time $(\mu \mathrm{s})$ & 15 & 2 & 4 & 5 & 6 & 6.3 & $\begin{array}{l}{ }^{3} 1,697 \\
{ }^{4} 1,994\end{array}$ \\
\hline Internal Votlage Reference & No & No & No & No & No & No & Yes \\
\hline DC Line Regulation@ @ IL,max $(\mathrm{mV} / \mathrm{V})$ & ${ }^{1}$ N. A. & ${ }^{1}$ N. A. & 0.327 & ${ }^{1}$ N. A. & 4.7 & ${ }^{1} \mathrm{~N} . \mathrm{A}$. & 4.68 \\
\hline DC Load Regulation $(\mu \mathrm{V} / \mathrm{mA})$ & ${ }^{1}$ N. A. & ${ }^{1}$ N. A. & 250 & 408 & 300 & 1 & $24.7-24.9$ \\
\hline FOM (fs) & 416 & 388.8 & 2520 & 42750 & 56.69 & 118.2 & $2.345^{7} 12.03$ \\
\hline
\end{tabular}

${ }^{1}$ Not available, ${ }^{2}$ Value obtained in load transient regulation, ${ }^{3}$ Simulated value obtained at $\mathrm{V}_{\mathrm{I}}=1.6 \mathrm{~V}$ for $\mathrm{I}_{\mathrm{L}}$ step-up variation from $150 \mathrm{~mA}$ to $0 \mathrm{~mA}$ with $1 \mu \mathrm{s}$ of rise time, ${ }^{4}$ Simulated value obtained at $\mathrm{V}_{\mathrm{I}}=1.6 \mathrm{~V}$ for $\mathrm{I}_{\mathrm{L}}$ step-down variation from $0 \mathrm{~mA}$ to $150 \mathrm{~mA}$ with $1 \mu \mathrm{s}$ of fall time, ${ }^{5}$ Values obtained with ideal voltage reference,

${ }^{6}$ Values obtained with internal voltage reference, ${ }^{7}$ Value obtained with internal voltage reference and calculated by using Eq. (32)

It is difficult to compare LDO regulators because generally each one is intended for a specific application. There are always tradeoffs between different performances such as high stability, fast transient response, low quiescent current which increases battery life and high power supply ripple rejection ratio which is not addressed in the proposed work. To determine the good LDO regulator from the performances inserted in Table 2, we base on the calculated value of the figure of merit FOM which includes the consumption from quiescent current, the capability of the LDO regulator to provide maximum current, the capacitance used to the output which must be as small as possible to save the surface and finally the maximum peak of the output voltage which must be minimized to avoid an abnormal operation of the circuit supplied by the LDO regulator. The proposed LDO regulator is better compared with the LDO regulators cited in the Table 2 , because it has the smallest value of FOM which is equal to 2.345 fs with ideal voltage reference, while FOM is equal to 12.03 fs with internal voltage reference.

\section{CONCLUSION}

In this paper, a novel internally frequency compensation technique called dual frequency compensation is proposed to enhance stability and transient response of the on-chip output capacitor three stage low-dropout linear voltage regulator. The proposed compensation technique guarantees the stability of 
the regulator system in a wide range of load current from 0 to $150 \mathrm{~mA}$ with small value of compensation capacitance of $2 \mathrm{pF}$ and maximum value of $100 \mathrm{pF}$ of load capacitance. The maximum quiescent current at full load condition of $150 \mathrm{~mA}$ is only $51.29 \mu \mathrm{A}$ when $\mathrm{LDO}$ regulator operates with $1.8 \mathrm{~V}$ of input supply voltage. Based on the calculated value of the FOM, the proposed LDO regulator exhibits good performance in terms of transient response compared to LDO regulators cited in this paper. The proposed circuit can be used to power a low voltage system on a chip of a smart wearable device. The proposed compensation method in this work degrades the power supply ripple rejection of the LDO regulator due to the decrease in the value of the $\mathrm{R}_{\mathrm{G}, \mathrm{P}}$ resistance. This problem has not been studied in this paper and will be addressed in future work.

\section{REFERENCES}

[1] Gjanci, J., Chowdhury, M.H. (2011). A hybrid scheme for on-chip voltage regulation in system-on-a-chip (SOC). IEEE Trans. VLSI Syst., 19(11): 1949-1959. http://dx.doi.org/10.1109/TVLSI.2010.2072997

[2] Liu, Q., Shu, W., Chang, J. S. (2017). A 400-MS/s 10-b 2-b/Step SAR ADC With 52-dB SNDR and 5.61-mW Power Dissipation in 65-nm CMOS. IEEE Transactions on Very Large Scale Integration (VLSI) Systems, 25: 3444-3454.

http://dx.doi.org/10.1109/TVLSI.2017.2747132

[3] Mehdaoui, Y., El Alami, R. (2018). DSP implementation of the Discrete Fourier Transform using the CORDIC algorithm on fixed point. Advances in Modelling and $\begin{array}{llll}\text { Analysis } & \mathrm{B}, & 61(3) \text { : } & \text { 123-126. }\end{array}$ http://dx.doi.org/10.18280/ama_b.610303

[4] Mehdaoui, Y., Malaoui, A., Gaga, A., El Alami, R., Mrabti, M. (2019). The efficiency of the CORDIC operator in the MIMO MC-CDMA receiver. Mathematical Modelling of Engineering Problems, 99. 104. https://doi.org/10.18280/mmep.060113

[5] Slamti, A., Qjidaa, H. (2011). A high performance regulated charge pump for USB-OTG transceiver. International Conference on Multimedia Computing and Systems. IEEE Xplore Digital Library. http://dx.doi.org/10.1109/ICMCS.2011.5945604

[6] Palumbo, G., Pappalardo, D. (2010). Charge pump circuits: an overview on design strategies and topologies. IEEE Circuits Syst. Mag., 10(1): 31-45. http://dx.doi.org/10.1109/MCAS.2009.935695

[7] Zheng, C., Ma, D. (2010). A 10MHz 92.1\%-efficiency green-mode automatic reconfigurable switching converter with adaptively compensated single-bound hysteresis control. IEEE International Solid-State Circuits Conference, pp. 204-205. http://dx.doi.org/10.1109/ISSCC.2010.5433986

[8] Mulligan, M.D., Broach, B., Lee T.H. (2007). A 3MHz Low-voltage buck bonverter with improved light load Efficiency. IEEE International Solid-State Circuits Conference. Digest of Technical Papers, 528-620. http://dx.doi.org/10.1109/ISSCC.2007.373527

[9] Hou, Y.C. (2017). Design of conditioning circuit for weak signal in through-casing resistivity logging. European Journal of Electrical Engineering, 197-208. https://doi.org/10.3166/EJEE.19.197-208

[10] Rincon-Mora, G.A. (2009). Analog IC design with low- dropout regulators (LDOs). 1st edn. The McGraw-Hill Companies, Inc. ISBN: 9780071608930

[11] Shi, C., Walker, B.C., Zeisel, E., Hu, B., McAllister, G.H. (2007). A highly integrated power management IC for advanced mobile applications. IEEE J. Solid-State Circuits, 42(8): 1723-1731. http://dx.doi.org/10.1109/CICC.2006.320982

[12] Annema, A.J., Nauta, B., van Langevelde, R., Tuinhout, H. (2005). Analog circuits in ultra-deep submicron cmos. IEEE J. Solid-State Circuits, 40(1): 132-143. http://dx.doi.org/10.1109/JSSC.2004.837247

[13] Lewyn, L.L., Ytterdal, T., Wulff, C., Martin, K. (2009). Analog circuit design in nanoscale cmos technologies. Proceedings of the IEEE, 97(10): 1687-1714. http://dx.doi.org/10.1109/JPROC.2009.2024663

[14] Patel, A.P., Rincon-Mora, G.A. (2010). High powersupply-rejection (PSR) current-mode low-dropout (LDO) regulator. IEEE Transactions on Circuits and Systems II: Express Briefs, 57(11). http://dx.doi.org/10.1109/TCSII.2010.2068110

[15] Leung, K.N., Mok, P. (2003). A capacitor-free cmos lowdropout regulator with damping-factor control frequency compensation. IEEE J. Solid-State Circuits, 38(10): 1691-1702.

http://dx.doi.org/10.1109/JSSC.2003.817256

[16] Leung, K.N., Mok, P. (2001). Analysis of multistage amplifier-frequency compensation. IEEE Transactions on Circuits and Systems I: Fundamental Theory and Applications, 48(9): http://dx.doi.org/10.1109/81.948432

[17] Lau, S.K., Mok, P., Leung, K.N. (2007). A low-dropout regulator for SoC with Q-reduction. IEEE Journal of Solid-State Circuits, 42(3): 658-664. http://doi.org/10.1109/JSSC.2006.891496

[18] Milliken, R., Silva-Martinez, E., Sanchez-Sinencio, E. (2007). Full on-chip CMOS low-dropout voltage regulator. IEEE Trans. Circuits Syst. I: Regul. Pap., 54(9): 1879-1890. http://dx.doi.org/10.1109/TCSI.2007.902615

[19] Giustolisi, G., Palumbo, G., Spitale, E. (2007). Ldo compensation strategy based on current buffer/amplifiers. 18th European Conference on Circuit Theory and Design: pp. 116-119. http://dx.doi.org/10.1109/ECCTD.2007.4529550

[20] Shen, L.G., Yan, Z.S., Zhang, X., Zhao, Y.F. (2008). A capacitor-less low-dropout regulator for soc with bidirectional asymmetric buffer. IEEE International Symposium on Circuits and Systems, pp. 2677-2680. http://dx.doi.org/10.1109/ISCAS.2008.4542008

[21] Giustolisi, G., Palumbo, G., Spitale, E. (2012). Robust miller compensation with current amplifiers applied to ldo voltage regulators. IEEE Trans. Circuits Syst. I: Regul. $\quad$ Pap., $59(9)$ : 1880-1893. http://dx.doi.org/10.1109/TCSI.2012.2185306

[22] Garimella, A., Rashid, M., Furth, P. (2010). Reverse nested miller compensation using current buffers in a three-stage ldo. IEEE Trans. Circuits Syst. II: Express Br., 57(4): http://dx.doi.org/10.1109/TCSII.2010.2043401

[23] Chong, S., Chan, P.K. (2013). A 0.9-/spl mu/A quiescent current output-capacitorless LDO regulator with adaptive power transistors in 65-nm CMOS. IEEE Trans. Circuits Syst. I: Regul. Pap., 60(4): 1072-1081. http://doi.org/10.1109/TCSI.2012.2215392 
[24] Carvajal, R., Ramirez-Angulo, J., Lopez-Martin, A., Torralba, A., Galan, J., Carlosena, A., Chavero, F. (2005). The flipped voltage follower: A useful cell for lowvoltage low-power circuit design. IEEE Trans. Circuits Syst. I: Regul. Pap., 52(7): 1276-1291. http://dx.doi.org/10.1109/TCSI.2005.851387

[25] Ramirez-Angulo, J., Valero-Bernal, M.R., Lopez-Martin, A., Carvajal, R., Torralba, A., Celma-Pueyo, S., Medrano-Marqués, N. (2013). The flipped voltage follower: Theory and applications. Analog/RF and Mixed-Signal Circuit Systematic Design, chapter 12: 269-287. http://dx.doi.org/10.1007/978-3-642-363290_12

[26] Manda, M., Pakala, S.H., Furth, P.M. (2017). A multiloop low-dropout FVF voltage regulator with enhanced load regulation. IEEE 60th International Midwest Symposium on Circuits and Systems (MWSCAS). http://doi.org/10.1109/MWSCAS.2017.8052847

[27] Tan, X.L., Koay, K.C., Chong, S.S., Chan, P.K. (2014). A FVF ldo regulator with dual-summed miller frequency compensation for wide load capacitance range applications. IEEE Trans. Circuits Syst. I: Regul. Pap., 61(5):

1304-1312.
[28] Abdi, F., Bastan, Y., Amiri, P. (2019). Dynamic currentboosting based FVF for output-capacitor-less LDO Regulator. Analog Integrated Circuits and Signal Processing. http://doi.org/10.1007/s10470-019-01479-x

[29] Razavi, B. (2017). Design of Analog CMOS Integrated Circuits. Second edition, by McGraw-Hill Education. ISBN 978-0-07-252493-2

[30] Erickson, R.W., Maksimovic, D. (2020). Fundamentals of Power Electronics. Springer Nature Switzeland. https://doi.org./10.1007/978-3-030-43881-4_21

[31] Nickalls, R.W. (1993). A new approach to solving the cubic: Cardan's solution revealed. Math. Gazette, 77(480): 354-359. https://doi.org/10.2307/3619777

[32] Slamti, A. Mehdaoui, Y., Chenouni, D., Lakhliai, Z. (2019). A sub-1V high PSRR OpAmp based $\beta$-multiplier CMOS bandgap voltage reference with resistive division. Indonesian Journal of Electrical Engineering and Computer Science, 15(1): 155-167. http://dx.doi.org/10.11591/ijeecs.v15.i1.pp155-167

[33] Hazucha, P., Karnik, T., Bloechel, B., Parsons, C., Finan, D., Borkar, S. (2005). Area-efficient linear regulator with ultra-fast load regulation. IEEE J. Solid-State Circuits, 40(4):

933-940. 